\title{
Consideration on the Necessity of Tritium Limit in Foods in Japan - Perspective on the Current Food Regulation
}

\author{
Kazuki IWAOKA, Naofumi AKATA ${ }^{1,2)}$, Masahiro HOSODA ${ }^{3)}$ and Shinji TOKONAMI \\ Institute of Radiation Emergency Medicine, Hirosaki University, 66-1 Honcho, Hirosaki, Aomori 036-8564, Japan \\ ${ }^{1)}$ National Institute for Fusion Science, 322-6 Oroshi-cho, Toki, Gifu 509-5292, Japan \\ ${ }^{2)}$ SOKENDAI (The Graduate University for Advanced Studies), 322-6 Oroshi-cho, Toki, Gifu 509-5292, Japan \\ ${ }^{3)}$ Hirosaki University Graduate School of Health Sciences, 66-1 Honcho, Hirosaki, Aomori 036-8564, Japan
}

(Received 19 January 2017 / Accepted 9 June 2017)

\begin{abstract}
The current radioactive cesium limit in food in Japan was established on the basis of a permissible dose relating to the food regulation in Japan $\left(1 \mathrm{mSvy}^{-1}\right)$ on April 2012. The current limit only accounts for the influence of ${ }^{134} \mathrm{Cs},{ }^{137} \mathrm{Cs},{ }^{90} \mathrm{Sr},{ }^{238} \mathrm{Pu},{ }^{239} \mathrm{Pu},{ }^{240} \mathrm{Pu},{ }^{241} \mathrm{Pu}$, and ${ }^{106} \mathrm{Ru}$; however, the contribution due to other radionuclides such as ${ }^{3} \mathrm{H}$ is not included. In this study, the principle focus was the influence of ${ }^{3} \mathrm{H}$ and the necessity for establishing permissible ${ }^{3} \mathrm{H}$ food contamination limits in the light of the Fukushima Daiichi Nuclear Power Plant (FDNPP) accident. It was found that no adjustment to ${ }^{3} \mathrm{H}$ limits in food was required due the FDNPP accident. This is because effective doses that include the contributions of ${ }^{3} \mathrm{H}$ would not exceed the permissible dose for food regulation in Japan as long as regulatory controls are performed using the current limits. The results and concepts in this study will prove helpful for food regulation when fusion reactors with ${ }^{3} \mathrm{H}$ are operational.
\end{abstract}

(c) 2017 The Japan Society of Plasma Science and Nuclear Fusion Research

Keywords: regulation, food limit, tritium, nuclear fusion, regulatory science, dose estimation

DOI: $10.1585 /$ prr.12.1305031

In April 2012, the current Japanese limits for radionuclide contaminations in food were established to mitigate internal exposure of the general public to radiation from contaminated foods due to the Fukushima Daiichi Nuclear Power Plant (FDNPP) accident. The current limits are $100 \mathrm{Bqkg}^{-1}$ for general foods as radioactive cesium $\left({ }^{134} \mathrm{Cs}+{ }^{137} \mathrm{Cs}\right)$. The current limits consider the influence of ${ }^{134} \mathrm{Cs},{ }^{137} \mathrm{Cs},{ }^{90} \mathrm{Sr},{ }^{238} \mathrm{Pu},{ }^{239} \mathrm{Pu},{ }^{240} \mathrm{Pu},{ }^{241} \mathrm{Pu}$, and ${ }^{106} \mathrm{Ru}$ and are set such that a total effective dose of radionuclides $\left({ }^{134} \mathrm{Cs},{ }^{137} \mathrm{Cs},{ }^{90} \mathrm{Sr},{ }^{238} \mathrm{Pu},{ }^{239} \mathrm{Pu},{ }^{240} \mathrm{Pu},{ }^{241} \mathrm{Pu}\right.$, and $\left.{ }^{106} \mathrm{Ru}\right)$ would not exceed $1 \mathrm{mSvy}^{-1}$ [1-4]. According to the Pharmaceutical Affairs and Food Sanitation Council (FSC), although other radionuclides (e.g., $\left.{ }^{3} \mathrm{H}\right)$ were released into environment, the contribution of these radionuclides in the environment was negligible due to the circumstances at the time of the establishment of the current limits. Therefore, these radionuclides were not considered while establishing the current limits [2]. Furthermore, it has been reported $[5,6]$ that the actual measurements of ${ }^{3} \mathrm{H}$ in the terrestrial environment are negligible. On the other hand, data relating to the concentration and kind of radionuclides in the marine environment were rarely available at the time of the establishment of the current limits because the contribution of these radionuclides in contaminating the marine environment was difficult to quantify [2]. The current limits were therefore established on an assumption of reasonable safety without any foundation on the actual contri-

author'se-mail: iwaoka@hirosaki-u.ac.jp bution of these radionuclides in contaminating the marine environment. The validation of this assumption is therefore seen as of immediate importance [2]. Considering the possibility that ${ }^{3} \mathrm{H}$ is leaking from the FDNPP to the marine environment even at present [7], the validation of the current limits including the influence of ${ }^{3} \mathrm{H}$ should be considered as a matter of priority. The consideration of these limits is also useful for preliminary research from the perspective of food regulation when fusion reactors become operational in the future.

In Japan, an effective dose of $1 \mathrm{mSvy}^{-1}$ that is consistent with the Codex Alimentarius Commission (CAC) [8,9] is adopted as the effective dose from which the current limits can be derived. A value of the concentration of radioactive cesium in the food derived from $1 \mathrm{mSvy}^{-1}$ is $120 \mathrm{Bqkg}^{-1}$ for $13-18$ years old males, which is the lowest value seen across all age categories as shown in Fig. 1. However, $100 \mathrm{Bqkg}^{-1}$ is adopted as the current limit by considering the excess dose for reasonable safety (hereafter, safety margin dose). If the dose of ${ }^{3} \mathrm{H}$ due to the FDNPP accident is less than the safety margin dose, then there is no need to set new ${ }^{3} \mathrm{H}$ food regulation limits because the total dose including exposure to ${ }^{3} \mathrm{H}$ does not exceed $1 \mathrm{mSvy}^{-1}$ under the regulation of the current limits. In this study, the necessity of limits for ${ }^{3} \mathrm{H}$ was considered by comparing the safety margin dose with the dose in the food contaminated by ${ }^{3} \mathrm{H}$ due to the FDNPP accident.

The safety margin doses were calculated using equations and parameters described in a report by the FSC [2]. 


\section{$1 \mathrm{mSvy}^{-1}$}

Considering intakes and conversion coefficients of the individual age categories.

\begin{tabular}{|c|c|}
\hline Age (year) Gender & Derived value $\left(\mathrm{Bqkg}^{-1}\right)$ \\
\hline$<1$ y & 460 \\
\hline $1-6 y$ Male & 310 \\
\hline $1-6 y$ Female & 320 \\
\hline $7-12$ y Male & 190 \\
\hline $7-12$ y Female & 210 \\
\hline $13-18$ y Male & 120 \\
\hline $13-18$ y Female & 150 \\
\hline$\geq 19 y$ Male & 130 \\
\hline$\geq 19 y$ Female & 160 \\
\hline Pregnant Female & 160 \\
\hline
\end{tabular}

These values are applicable 1 year after the FDNPP accident.

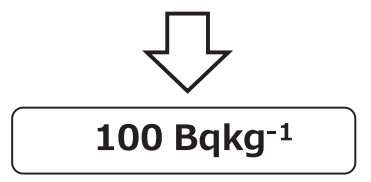

Fig. 1 Values derived from $1 \mathrm{mSvy}^{-1}$ [2].

Due to the complexity of these equations, Microsoft Excel was used to facilitate the dose calculation. The accuracy of this method has been confirmed as values of limits derived using this method are consistent with those found in the FSC report [2].

For the purpose of dose calculation, it was assumed that the principle foods contaminated with ${ }^{3} \mathrm{H}$ were marine products because ${ }^{3} \mathrm{H}$ due to the FDNPP accident continues to leak into the ocean $[7,10]$ and the actual measurements of ${ }^{3} \mathrm{H}$ in the terrestrial environment are negligible $[5,6]$. Dose calculations were performed on the basis of the assumption that an individual consumes marine products that originate from the FDNPP harbor every day. Effective doses were then calculated using Eq. (1) together with recorded data:

$$
E=D \times I \times T \times F \times A,
$$

where $E$ is the annual effective dose of ${ }^{3} \mathrm{H}\left(\mathrm{Svy}^{-1}\right), D$ is the dose coefficient $\left(\mathrm{SvBq}^{-1}\right), I$ is the food intake of marine products $\left(\mathrm{kgd}^{-1}\right), T$ is the duration of intake $=365$ $\left(\mathrm{dy}^{-1}\right), F$ is the transfer factor of ${ }^{3} \mathrm{H}$ from water to marine products (-), and $A$ is the activity concentration of ${ }^{3} \mathrm{H}$ in water $\left(\mathrm{Bqkg}^{-1}\right)$. The values of dose coefficient for each age category in the ICRP Publication were used for $D$ (as seen in Table 1) [11,12]. The value of marine products intake for each age category in the FSC report was used for $I$ (Table 1) [2]. The value of $F$ from water to marine products was assumed to be 1 [13]. The value of $A$ was assumed to be $3600 \mathrm{Bqkg}^{-1}$, which is the maximum value recorded for
Table 1 Values of intakes and dose coefficients.

\begin{tabular}{ccc}
\hline Age (year) Gender & $\begin{array}{c}\text { Intakes } \\
I\left(\mathrm{kgd}^{-1}\right)\end{array}$ & $\begin{array}{c}\text { Dose coefficients } \\
D\left(\mathrm{SvBq}^{-1}\right)\end{array}$ \\
\hline$<1 \mathrm{y}$ & 0.0097 & $1.2 \times 10^{-10}$ \\
1-6y Male & 0.038 & $7.3 \times 10^{-11}$ \\
1-6y Female & 0.040 & $7.3 \times 10^{-11}$ \\
7-12y Male & 0.076 & $5.7 \times 10^{-11}$ \\
7-12y Female & 0.067 & $5.7 \times 10^{-11}$ \\
13-18y Male & 0.082 & $4.2 \times 10^{-11}$ \\
13-18y Female & 0.072 & $4.2 \times 10^{-11}$ \\
$\geq 19 y$ Male & 0.11 & $4.2 \times 10^{-11}$ \\
>19y Female & 0.090 & $4.2 \times 10^{-11}$ \\
Pregnant Female & 0.054 & $4.2 \times 10^{-11}$ \\
\hline
\end{tabular}

seawater inside the FDNPP harbor [7].

The results of calculations for the safety margin doses are shown in Table 2. One year after the accident, the safety margin dose of 13-18 years old males was $0.20 \mathrm{mSvy}^{-1}$, which was the lowest value across all age categories. The safety margin dose for 13-18 years old males in the range 2 - 100 years after the FDNPP accident was also below $0.20 \mathrm{mSvy}^{-1}$ with safety margin doses increasing with elapsed years after the accident in most age categories. The results of doses obtained from recorded data of ${ }^{3} \mathrm{H}$ are shown in Table 3. Although these doses were based on a reasonable assumption of safety (as individuals consume marine products living in the FDNPP harbor), the maximum value of the dose in each age category was $0.0061 \mathrm{mSvy}^{-1}$, which is less than $0.20 \mathrm{mSvy}^{-1}$ (the safety margin doses).

It is seen that the dose due to food ingestion including contributions of ${ }^{3} \mathrm{H}$ would therefore not exceed $1 \mathrm{mSvy}^{-1}$, which is the effective dose for food regulation in Japan. This is valid as long as regulatory controls are performed using the current limits for radioactive cesium. In addition, because measures such as the installation of impervious walls for the prevention of leakage of radionuclides from the FDNPP are being taken [14], the influence of ${ }^{3} \mathrm{H}$ from the FDNPP will decrease in future. The results presented in this work therefore suggest that at present there is no need for new radioactive limits for food contamination due to ${ }^{3} \mathrm{H}$ as a result of the FDNPP accident.

In summary, this study describes an investigation of the necessity for a re-evaluation of radioactive contamination food limits for ${ }^{3} \mathrm{H}$ due to the FDNPP accident. Moreover, it was found that at present, there is no need for new radioactive contamination food limits for ${ }^{3} \mathrm{H}$ because the dose due to food ingestion (including contributions due to ${ }^{3} \mathrm{H}$ ) would not exceed $1 \mathrm{mSvy}^{-1}$, which is the effective dose for food regulation in Japan. The use of ${ }^{3} \mathrm{H}$ is 
Table 2 Safety margin doses using current limits.

\begin{tabular}{|c|c|c|c|c|c|c|c|c|c|c|c|c|}
\hline \multirow[t]{2}{*}{ Age (year) Gender } & \multicolumn{12}{|c|}{ Safety margin dose $\left(\mathrm{mSvy}^{-1}\right)$} \\
\hline & $1^{*}$ & $2^{*}$ & $3^{*}$ & $4^{*}$ & $5^{*}$ & $6^{*}$ & $10^{*}$ & $20^{*}$ & $30^{*}$ & $50^{*}$ & $75^{*}$ & $100^{*}$ \\
\hline$<1 \mathrm{y}$ & 0.71 & 0.71 & 0.71 & 0.71 & 0.71 & 0.71 & 0.71 & 0.71 & 0.71 & 0.71 & 0.71 & 0.71 \\
\hline 1-6y Male & 0.63 & 0.63 & 0.63 & 0.64 & 0.64 & 0.64 & 0.65 & 0.65 & 0.65 & 0.65 & 0.65 & 0.65 \\
\hline 1-6y Female & 0.64 & 0.64 & 0.64 & 0.65 & 0.65 & 0.65 & 0.66 & 0.66 & 0.66 & 0.66 & 0.66 & 0.66 \\
\hline $7-12$ y Male & 0.44 & 0.44 & 0.45 & 0.45 & 0.45 & 0.46 & 0.46 & 0.47 & 0.47 & 0.47 & 0.47 & 0.48 \\
\hline $7-12$ y Female & 0.48 & 0.49 & 0.49 & 0.50 & 0.50 & 0.50 & 0.51 & 0.51 & 0.51 & 0.51 & 0.52 & 0.52 \\
\hline 13-18y Male & 0.20 & 0.21 & 0.22 & 0.23 & 0.23 & 0.24 & 0.25 & 0.26 & 0.26 & 0.26 & 0.27 & 0.27 \\
\hline 13-18y Female & 0.32 & 0.33 & 0.34 & 0.34 & 0.35 & 0.35 & 0.36 & 0.37 & 0.37 & 0.37 & 0.37 & 0.38 \\
\hline$\geq 19 y$ Male & 0.22 & 0.23 & 0.25 & 0.26 & 0.27 & 0.28 & 0.3 & 0.31 & 0.31 & 0.31 & 0.31 & 0.32 \\
\hline$\geq 19 y$ Female & 0.36 & 0.37 & 0.39 & 0.4 & 0.41 & 0.41 & 0.43 & 0.43 & 0.44 & 0.44 & 0.44 & 0.44 \\
\hline Pregnant Female & 0.34 & 0.36 & 0.37 & 0.38 & 0.39 & 0.39 & 0.41 & 0.42 & 0.42 & 0.42 & 0.42 & 0.42 \\
\hline
\end{tabular}

*: Years after the FDNPP accident

Table 3 Effective doses of ${ }^{3} \mathrm{H}$.

\begin{tabular}{cc}
\hline Age (year) Gender & Effective dose $\left(\mathrm{mSvy}^{-1}\right)$ \\
\hline$<1$ y & 0.0015 \\
$1-6 y$ Male & 0.0036 \\
1-6y Female & 0.0038 \\
7-12y Male & 0.0057 \\
7-12y Female & 0.0050 \\
$13-18$ y Male & 0.0045 \\
$13-18 y$ Female & 0.0040 \\
$\geq 19 y$ Male & 0.0061 \\
$\geq 19 y$ Female & 0.0050 \\
Pregnant Female & 0.0030 \\
\hline
\end{tabular}

presently being evaluated as a stable power source at a number of facilities with a view to nuclear fusion reactors becoming operational in the future [15]. When fusion reactors employing ${ }^{3} \mathrm{H}$ are put into effect, the necessity of new regulation regarding ${ }^{3} \mathrm{H}$ exposure and amendments to the Food Sanitation Act in Japan will become necessary. At that time, the results and concepts highlighted in this study will provide an important starting point for future investigations.
This work was partially supported by NIFS Collaboration Research Program (NIFS15KLEA023). Other parts of this work were supported by JSPS KAKENHI Grant Numbers JP16K16234.

[1] K. Iwaoka, Health Physics 111, 471 (2016).

[2] FSC, Pharmaceutical Affairs and Food Sanitation Council, Report of Committee on Radionuclides in foods (2012).

[3] K. Iwaoka, Clean Technology 23, 40 (2012).

[4] K. Iwaoka, Food Sanitation Research 63, 29 (2013).

[5] H. Kakiuchi et al., Scientific Reports 2, 947 (2012).

[6] T. Matsumoto et al., Science of the Total Environment 445446, 365 (2013).

[7] http://www.tepco.co.jp/nu/fukushima-np/f1/smp/2016/ images4/2tb-east_16122201-j.pdf

[8] CAC, CODEX STAN 193-1995 (2010).

[9] CAC, Fact Sheet on Codex Guideline Levels for Radionuclides in Foods Contaminated Following a Nuclear or Radiological Emergency (2011).

[10] http://www.tepco.co.jp/nu/fukushima-np/handouts/2013/ images/handouts_130722_08-j.pdf

[11] ICRP, ICRP Publication 72 (1995).

[12] ICRP, ICRP Publication 119 (2012).

[13] IAEA, Technical Report Series 422 (2004).

[14] http://www.tepco.co.jp/decommision/planaction/ waterprocessing/index-j.html

[15] S. Konishi et al., Fusion Science and Technology 60, 1211 (2011). 